\title{
A Review on Anti-Nutritional Factors
}

\section{Nitin Vikram ${ }^{1}$, Sunil Kumar Katiyar ${ }^{1}$, Chandra Bhushan Singh', Raja Husain ${ }^{2}$ and Lokesh Kumar Gangwar ${ }^{3}$}

\author{
${ }^{1}$ Department of Agriculture, Zila Parishad Krishi Mahavidyalaya, Banda (U.P.)-210001 \\ ${ }^{2}$ Himalayan University, Itanagar, Arunachal Pradesh-791111, India \\ ${ }^{3}$ Sardar Vallabh Bhai Patel University of Agriculture and Technology, \\ Modipuram, Meerut-250110, India
}

*Corresponding author

\begin{abstract}
A B S T R A C T
This review is focuses on the anti-nutritional factors in plant metabolism and how they are beneficial to the plant defense system and harmful or beneficial to humans or animals and also how to reduce their quantity in materials. The anti-nutritional factors can be defined as those substances generated in natural food substances by the normal metabolism of species and by different mechanisms e.g. inactivation of some nutrients, diminution of the digestive process or metabolic utilization of feed, which exert effects contrary to optimum nutrition. Anti-nutritional factors are natural or synthetic compounds that interferes the absorption and metabolism of nutrients. Nutrition studies focus on these antinutrients commonly found in food sources and beverages e.g. polyphenols, oxalic acid, oxalates, glucosinolates, amylase inhibitor, lipase inhibitor, protease inhibitors and phytic acid etc. Plants commonly synthesize a range of secondary metabolites as part of their protection against attack by herbivorous, insects and pathogens or as means to survive in adverse growing conditions (Bora, 2014). Synthetic substances present in nourishment test and which have been accounted for with some level of poisonous quality in humanity incorporate aflatoxin, hemagglutinin and cyanogenic glycosides. Harmfulness is the after effect of the connection between three factors to be specific the kind of living being, a grouping of poison and time of length (Akande, et al. 2010). For instance, in a portion of the nourishments which contain inborn standards, handling strategies have been produced which make them alright for human utilization. Accordingly, this paper is meat to survey antinutritioanl factors and their impact on mineral retention.
\end{abstract}

\section{Keywords}

Anti-Nutritional

Factors, Plant

metabolism, Plant

defense system

Article Info

Accepted:

10 April 2020

Available Online:

10 May 2020

\section{Introduction}

Plants have developed a number of survival mechanisms to reduce the chances of their seeds being eaten or digested by insects, birds or other animals.
One defense mechanism is the production of compounds called antinutrients or antinutritional factors (ANFs), which are toxic to the animals or inhibit digestion of the seeds. Health benefits to fish have not been 
reported. Therefore, antinutritional factors are an important consideration in animal and fish nutrition because many feed ingredients used in animal and fish feeds are produced from grains, legumes and oilseeds (Krammer et al., 1984). Two main approaches to eliminating ANFs in feed ingredients are the destruction or removal of ANFs during seed processing and changing specific genetic characteristics of the seeds. Some antinutritional factors can be destroyed or removed through certain conditions (e.g. High temperature extrusion processing of soybean or canola meal and solvent extraction of whole oilseeds or their protein rich by-products following oil extraction).

Plants commonly synthesize a range of secondary metabolites as part of their protection against attack by herbivores, insects and pathogens or as a means to survive in adverse growing conditions. If farm or domestic animals or humans consume these plants, these compounds may cause adverse physiological effects. The terms antinutrient or natural toxicant have been widely employed to describe plant defense metabolites in the structures of the individual compounds, which can range from high molecular weight proteins to simple amino acids and oligosaccharides. Legumes are a rich source of antinutrients in the human diet. A number of so called antinutrients have been shown to possess beneficial- anticancer, antimicrobial- properties which also vary according to their level in the diet. Brief reference to such effects are also included because a pressing challenge to scientists is to identify optimal levels for maximizing the benefit to risk ratio, thereby providing plant breeders, molecular biologists and food processors with additional goals for maximizing overall product quality. Methods for reducing antinutrients in food are presented according to their physical (dehulling/ cooking; autoclaving/pressure cooking; dry roasting; soaking; milling/ultrafiltration) or biochemical (enzyme processing; fermentation; germination) character. Given the importance of antinutrients to the developing plant the complete removal of these compounds by breeding or biotechnological programs, even if possible, may produce plants with poorer growth and lower yield characteristics (Khokhar and Apenten, 2014; Bora, 2014). The structures of the antinutrients and their chemical properties, especially their heat lability, dictate which physical processes will most effective in their reduction or removal, thereby minimizing adverse biological effects. Plant food also contains proteinaceous antinutrientis including protease inhibitors, phytohaemagglutinins, lectins, $\alpha$-amylase inhibitors and allergens. Consumption of raw legumes leads to nausea, vomiting and diarrhea. More chronic effects of protein antinutrients include pancreatitis and some from intestinal cancer although such effects have not been proven unequivocally. A number of antinutrients have been shown to possess beneficial properties for example; anticancer, antimicrobial. Such compounds are of increasing interest in the fields of biochemistry, medicine, pharmacology and nutrition (Akande, et al., 2010).

Plant breeders or molecular biologists wish to manipulate levels of these compounds to obtain optimal effect during cultivation while ensuring the quality of the harvested crop. The review also emphasizes the effect of common food processing techniques on legume antinutrients. Legumes commonly used as food include soybean (Glycine max), black gram (Phaseolus mungo), cowpea (Vigna unguiculata), dry bean (Phaseolus vulgaris), winged bean (Psophocarpus tetragonolobus), chickpea (Cicer arietinum), horse gram (Dolichos biflorus), moth bean (Vigna aconitifolia), pigeon pea (Cajanus cajan), fava bean, and grass pea. Although the 
total area of cultivation is believed to be similar for cereals and legumes the latter contain a higher percentage of protein. Legume seeds provide a relatively affordable protein source in developing countries (Khokhar and Apenten, 2014).

Physical and chemical methods employed to reduce or remove antinutritional factors include soaking, cooking, germination, fermentation, selective extraction, irradiation and enzymic treatment. Using a combination of abrasion and soaking, the amount of quinoa saponins was reduced by up to $100 \%$. Industrial processes, including canning, toasting, fractionation and isolation of protein concentrates have also been shown to be effective in reducing or removing antinutritional factors (Van Eys et al., 2004). However it should be borne in mind that processing can also introduce undesirable compound, for example volatile aldehydes and ketones and peroxides as a direct result of lipid oxidation or reduce levels of desirable compounds e.g. protein and essential minerals.

\section{Physical processes to reduce the anti-nutritional factor's effects:}

\begin{tabular}{|c|c|}
\hline Physical Processing & Comments \\
\hline $\begin{array}{l}\text { Autoclaving, pressure } \\
\text { cooking, steaming }\end{array}$ & $\begin{array}{l}\text { Heating at ultrahigh temperatures }\left(>100^{\circ} \mathrm{C}\right) \text {. Performance dependent on temperature, } \\
\text { moisture, pressure relations. }\end{array}$ \\
\hline Blanching & Mild boiling $\left(75^{\circ} \mathrm{C}-95^{\circ} \mathrm{C}\right)$ to inactivate endogenous enzymes and avoid cooking \\
\hline Ordinary cooking & $\begin{array}{l}\text { Usually proceeded by soaking or another domestic processing, de-hulling, germination } \\
\text { fermentation and so on. }\end{array}$ \\
\hline Extrusion & $\begin{array}{l}\text { A form of high temperature short time (HTST) processing involving a combination of } \\
\text { high temperature, pressure and shear processing }\end{array}$ \\
\hline Roasting & Dry heating at $120^{\circ} \mathrm{C}-250^{\circ} \mathrm{C}$ \\
\hline Soaking & Exposure to water and salt solutions with or without additive to encourage ANF loss \\
\hline $\begin{array}{l}\text { Processing chemical and } \\
\text { chemical modification }\end{array}$ & $\begin{array}{l}\text { Treatment with thiols, sulphite, Cu-salts ( } \pm \text { ascorbic acid). Chemical modification via } \\
\text { acylation, succinylation }\end{array}$ \\
\hline
\end{tabular}

\section{Phytate}

Phytate [is also known as Inositol hexakisphosphate (InsP6)] is the salt form of phytic acid, are found in plants, animals and soil. It is primarily present as salt of the mono- and divalent cations $\mathrm{K}^{+}, \mathrm{Mg}^{2+}$, and $\mathrm{Ca}^{2+}$ and accumulates in the seeds during the ripening period. Phytate is regarded as the primary storage form of both phosphate and inositol in plant seeds and grains. In addition, phytate has been suggested to serve as a store of cations, of high energy phosphoryl groups, and by chelating free iron, as a potent natural anti-oxidant (Mueller, 2001). In monocotyledons such as wheat and rice, PA is present in the germ of corn and in the aleurone or bran layer allowing an easy separation by milling.
However, in dicotyledonous seeds such as legumes, nuts and oilseeds, PA is found closely associated with proteins and is often isolated or concentrated with protein fraction of these foods.

\section{Oxalate}

A salt formed from oxalic acid is known as an Oxalate: for example, Calcium oxalate, which has been found to be widely distributed in plants. Strong bonds are formed between oxalic acid, and various other minerals, such as Calcium, Magnesium, Sodium and Potassium. This chemical combination results in the formation of oxalate salt. The insoluble calcium oxalate has the tendency to precipitate (or solidify) in the Kidneys or in the Urinary tract, thus forming sharp-edged 
calcium oxalate crystals when the levels are high enough. These crystals play a role to the formation of Kidney stones formation in the urinary tract when the acid is excreted in the urine (Nachbar et. al. 2000). They also cause muscular weakness and paralysis. Oxalates also cause gastrointestinal tract irritation, blockage of the renal tubules by calcium oxalate crystals, development of urinary calculi and hypocalcaemia. Oxalates cause nephrotic lesions in the kidney.

\section{Saponins}

Saponins are secondary compounds that are generally known as non-volatile, surface active compounds which are widely distributed in nature, occurring primarily in the plant kingdom. They are structurally diverse molecules that are chemically referred to as triterpene and steroid glycosides. They consist of nonpolar aglycones coupled with one or more monosaccharide moieties. This combination of polar and non-polar structural elements in their molecules explains their soap-like behavior in aqueous solutions. The structural complexity of saponins results in a number of physical, chemical and biological properties, which includes sweetness and bitterness, foaming and emulsifying properties, pharmacological and medicinal properties, haemolytic properties, as well as antimicrobioal, insecticidal and molluscicidal activities (Shanthakumari et al., 2008). They significantly inhibit acrosine activity of human sperms and the spermicidal effect is attributed to strong damage of the spermal plasma membrane. Saponins are characterized by bitter taste and foaming properties. Saponins occur in a broad range of plants consumed in the human diet, including legumes (soya, peas and beans), root crops (potato, yarns, asparagus and alliums) as well as in oats, sugar beet, tea, and many medicinal herbs (such as ginseng). Within grain legumes the saponin content varies between $0.5 \%$ and $5 \%$ dry weight with soybean being the most important dietary source (Table).

Table.1 Saponin levels in some legumes seeds and ginseng

\begin{tabular}{|l|c|}
\hline Source & Saponins (\% dry weight) \\
\hline Soybean & 5.6 \\
\hline Chickpea & 3.6 \\
\hline Lucerne (Medicago sativa) & 2.5 \\
\hline Lupine & 1.5 \\
\hline Quinoa & $0.02-0.04(0.47-1.13)^{*}$ \\
\hline Ginseng & $0.5-3.0$ \\
\hline
\end{tabular}

*values for sweet and bitter varieties.

\section{Lectins}

Lectin comes from the Latin word "legere", which means "to selet". Lectins have the ability to bind carbohydrates. Nowadays proteins that can agglutinate red blood cells with known sugar specificity are referred to as "lectins" (Fereidoon, 2014). They can bind to the carbohydrate moieties on the surface of erythrocytes and agglutinate the erythrocytes, without altering the properties of the carbohydrates. Lectins are glycoproteins widely distributed in legumes and some certain oil seed (including soybean) which possess an affinity for specific sugar molecules and are characterized by their ability to combine with carbohydrate membrane receptors.

Lectins have the capability to directly bind to 
the intestinal muscosa, interacting with the enterocytes and interfering with the absorption and transportation of $0.01 \%$ free gossypol within some low gossypol cotton nutrients (particularly carbohydrates) during digestion and causing epithelial lesions within the intestine. Although lectins are usually reported as being labile, their stability varies between plant species, many lectins being resistant to inactivation by dry heat and requiring the presence of moisture for more complete destruction.

\section{Alkaloids}

Alkaloids are one of the largest groups of chemical compounds synthesized by plants and generally found as plant acids such as oxalic, malic, tartaric or citric acid. Alkaloids are small molecules, common to about 15 to 20 per cent of all vascular plants, usually comprising several carbon rings with side chains, one or more of the carbon atoms being replaced by nitrogen(Felix and Mello, 2000). Insects and hervibores are usually repulsed by the potential toxicity and bitter taste of alkaloids (Fereidon, 2014). Alkaloids are considered to be anti-nutrients because of their action on the nervous system, disrupting or inappropriately augmenting electrochemical transmission. Indeed, the physiological effects of alakaloids have on humans are very evident. Cholinesterase is greatly inhibited by glycoalakloids, which also cause symptoms of neurological disorder. Other toxic action includes disruption of the cell membrane in the gastrointestinal tract (Fermando et al., 2012; Habtamu and Nigussie, 2014) Alkaloids cause gastrointestinal and neurological disorders. The glycoalkaloids, solanine and chaconine present in potato and Solanum spp. are haemolytically active and toxic to humans. Some of the toxicological manifestations of potato glycoalkaloids involve gastrointestinal upsets and neurological disorders. Glycoalkaloids are reported to cause haemolysis and toxicity to humans. Some plant alkaloids are reported to cause infertility.

\section{Protease inhibitors}

Protease inhibitors are widely distributed within the plant kingdom, including the seed of most cultivated legumes and cereals. Protease inhibitors have the ability to inhibit the activity of proteolytic enzymes within the gastrointestinal tract of animals. Due to their particular protein nature, protease inhibitors may be easily denatured by heat processing although some residual activity may still remain in the commercially produced products. The antinutrient activity of protease inhibitors is associated with growth inhibition and pancreatic hypertrophy. Potential beneficial effects of protease inhibitors remain unclear, although lower incidents of pancreatic cancer have been observed in populations where the intake of soybean and its products is high (Giri and Kachole, 2004). While protease inhibitors have been linked with pancreatic cancer in animal studies, they may also act as anticarcinogenic agents. The Bowman-Birk inhibitors derived from soybean have shown to inhibit or prevent the development of chemicallyinduced cancer of the liver, lung, colon, oral and esophagus (Finotti et al., 2006). Trypsin inhibitor and chymotrypsin inhibitor are protease inhibitors occurring in raw legumes seed (Friedman et al., 2003). Trypsin (protease inhibitor) causes pancreatic enlargement and growth depression. Haemagluttinins are proteins known for agglutinating red blood cells.

\section{Cyanogenic glycosides}

The cyanogenic glycosides belong to the products of secondary metabolism, to the natural products of plants. These compounds are composed of an $\alpha$-hydroxynitrile type 
aglycone and of a sugar moiety (mostly Dglucose). Cyanogenic glucosides $(\alpha-$ hydroxynitrile glucosides) are derived from the five protein amino acids Valine, Isoleusine, Leusine, Phenylalanine and Tyrosine and from the nonproteinogenic amino acid cyclopentyl glycine. Their general function in plants is dependent on activation by $\beta$-glucosides to release toxic volatile $\mathrm{HCN}$ as well as ketones or aldehydes to fend off herbivore and pathogen attack(Golden 2009). Cyanogenic glucoside on hydrolysis yields toxic hydrocyanic acid (HCN). The cyanide ions inhibit several enzyme systems; depress growth through interference with certain essential amino acids and utilization of associated nutrients. They also cause acute toxicity, neuropathy and death.

\section{Tannins}

Tannin is an astringent, bitter plant polyphenolic compound that either binds or precipitates proteins and various other organic compounds including amino acids and alkaloids. These compounds are present in numerous tree and shrub foliages, seeds and agro-industrial by-products.

Tannins have a property of binding to protein to form reversible and irreversible complexes due to the existence of a number of phenolic hydroxyl groups. Tannins are known to be responsible for decreased feed intake, growth rate, feed efficiency and protein digestibility in experimental animals. If tannin concentration in the diet becomes too high, microbial enzyme activities including cellulose and intestinal digestion may be depressed (Habtamu and Nigussie, 2014).

Tannins bind dietary protein and digestive enzymes to form complexes that are not readily digestible. They also cause decreased palatability and reduced growth rate.

\section{Mycotoxins}

Mycotoxins are those secondary metabolites of fungi that have the capacity to impair animal health and productivity (D'Mello and Macdonald, 1998). Mycotoxin contamination of forages and cereals frequently occurs in the field following infection of plants with particular pathogenic fungi or with symbiotic endophytes. Contamination may also occur during processing and storage of harvested products and feed whenever environmental conditions are appropriate for spoilage fungi. Moisture content and ambient temperature are key determinants of fungal colonization and mycotoxin production. Claviceps, Neotyphodium, Fusarium and Alternaria are classical representatives of field fungi while Aspergillus and Penicillium exemplify storage organisms. Thus, Aspergillus flavus, A. parasiticus and A. ochraceus readily proliferate under warm, humid conditions, while Penicillium expansum and $P$. verrucosum are essentially temperate fungi. Consequently, the Aspergillus mycotoxins predominate in plant products emanating foods, particularly cereal grains (D'Mello and Macdonald, 1998).

\section{Aflatoxins and gossypol}

This group includes aflatoxin B1, B2, G1 and G2 (AFB1, AFB2, AFG1 and AFG2, respectively). In addition, aflatoxin M1 (AFM1) has been identified in the milk of dairy cows consuming AFB1- contaminated feeds. The aflatoxin Aspergilli are generally regarded as storage fungi, proliferating under conditions of relatively high moisture/humidity and temperature. Aflatoxin contamination is therefore, almost exclusively confined to tropical feeds such as oil seed by products derived from groundnuts, cotton seed and palm kernel. 
Aflatoxin contamination of maize is also an important problem in warm humid regions where A. flavus may infect the crop prior to harvest and remain viable during storage (D’Mello and Macdonald, 1998).Gossypol pigment in cotton seed occurs free and bound forms. In whole seeds, gossypol exists essentially in the free form, but variable amount may bind with protein during processing to yield inactive forms. Free gossypol is the toxic entity and causes organ damage, cardiac failure and death. Cotton seed meal fed to bulls can include increased sperm abnormalities and decreased sperm production (D'Mello and Macdonald, 1998). At the physiological level, gossypol reduces oxygen availability in the blood. Other physiological abnormalities include hypertrophy and dilution of heart muscles and changes in electrocardiogram.

\section{Nitrates}

Factors affecting the severity of nitrate poisoning are the rate and quantity of consumption, type of forage, energy level or adequacy of the diet. Fahey and Jung, 1989 reported that sheep and cattle fed poor diets seem to be more susceptible to nitrate poisoning. Nitrate poisoning is better described as nitrite poisoning. When livestock consume forages, nitrate is normally converted in the rumen from nitrate to nitrite to ammonia to amino acid to protein. When forages have an unusually high concentration of nitrate, the animal cannot complete the conversion and nitrite accumulates. Nitrite is absorbed into the bloodstream directly through the rumen wall and converts haemoglobin (the oxygen carrying molecule) in the blood to methanemoglobin, which cannot carry oxygen. The blood turns to a chocolate brown colour rather than the usual bright red. An animal dying from nitrate (nitrite) poisoning actually dies from asphyxiation, or lack of oxygen (Fahey and
Jung, 1989). Nitrate accumulation can have serious deleterious effects. Within the gastrointestinal tract nitrate $\left(\mathrm{NO}_{3}{ }^{-}\right)$is reduced to nitrite $\left(\mathrm{NO}_{2}{ }^{-}\right)$which is absorbed into the blood stream where it binds with haemoglobin oxidizing ferrous iron to ferric iron to form methaemoglobin. This form of haemoglobin complex is incapable of $\mathrm{O}_{2}$ transport. The result is Anoxia, specifically referred to as methaemoglobinaemia.

\section{Polyphenols}

These secondary plant metabolites are distributed ubiquitously within plant foods (vegetables, cereals, legumes, fruits, nuts and so on) and beverages (tea, wine, cocoa, and so on). Their levels vary greatly even between cultivars of the same species. Environmental factors such as light, germination, degree of ripeness, variety, processing and storage and genetic factors can influence the levels. Currently there is no accurate information available on dietary intake of polyphenols; only a few estimates are available which are 1g/day (US), $23 \mathrm{mg} /$ day (Dutch) and $28 \mathrm{mg} /$ day (Denmark).Oxidation products of phenolic compounds are known to be involved in plant defense against insects, pests and invading pathogens including bacteria, fungi and viruses; polymeric compounds appear to be more toxic toward phytopathogens than their precursor low molecular weight monomers such as chlorogenic acid. Polyphenoloxidase catalyzed polymerization helps seal the injured plant surface and begin the healing process.

\section{Lathyrogens}

$\beta$-N-oxalyl-L- $\alpha, \beta$-diaminopropionic acid $(\beta$ ODAP or BOAA), a naturally occurring amino acid, possesses potent neurotoxic activity and has been shown to be responsible for outbreaks of neurolathyrism following 
consumption of Lathyrus sativus. $\beta$-ODAP occurs naturally as two isomeric forms with the $\alpha$-form being approximately $5 \%$ of the total. According to toxicological studies, this isomer is less toxic than the major, $\beta$-isomer. The level of $\beta$-ODAP in dry seed varies considerable according to genetic factors and environmental conditions. L. sativa grown in nutrient solutions that are zinc deficient or rich in ferrous iron produced seed with elevated levels of $\beta$-ODAP. $\beta$-ODAP is biosynthesized during the ripening of the seed and is further increased during germination.

\begin{tabular}{|c|c|c|}
\hline Name & Toxic compounds & Adverse effects \\
\hline Carrot & $\begin{array}{l}\text { Carota-toxin (polyacetyl lenic } \\
\text { alchol) }\end{array}$ & Neurotoxic symptoms \\
\hline Lettuce & Nitrates, alkaloids & Methemglobinaemia \\
\hline $\begin{array}{l}\text { Brassica } \\
\text { (cruciferous } \\
\text { vegetables) }\end{array}$ & $\begin{array}{l}\text { Glucosinolates, choline-esterase } \\
\text { inhibitor, S-methyl cysteine } \\
\text { sulfoxides }\end{array}$ & Goiter, digestive disorders \\
\hline Beets, spinach & $\begin{array}{l}\text { Oxalates, Nitrates, Phytate, Tanins, } \\
\text { Nitrosamine }\end{array}$ & $\begin{array}{l}\text { Methemglobinaemia reduces } \\
\text { bioavailability of certain minerals }\end{array}$ \\
\hline Sweet potato & Ipomeamarone & Enzyme inhibitors \\
\hline Watermelon & Serotonin & Elevates blood pressure \\
\hline $\begin{array}{l}\text { Pumpkin and } \\
\text { squashes }\end{array}$ & Choline-esterase inhibitor & Neurotoxic \\
\hline $\begin{array}{l}\text { Legumes } \\
\text { (vegetables) }\end{array}$ & $\begin{array}{l}\text { Lectins, Cynogenic glucosides, } \\
\text { Haemagglutinins, trypsin, Amylase, } \\
\text { Glucose-6-P-dehydrogenase } \\
\text { inhibitor, compounds having anti- } \\
\text { vitamin properties (Vitamin A, E } \\
\text { and D) }\end{array}$ & Allergens \\
\hline Asparagus & Saponins, choline-esterase inhibitor & Neurotoxic \\
\hline $\begin{array}{l}\text { Solanaceous } \\
\text { vegetables }\end{array}$ & Alkaloids & Birth defect, protease inhibitor \\
\hline Potato & Solanine and Chaconine & Invertase inhibitor \\
\hline Tomato & Tomatine & Gastric discomfort \\
\hline $\begin{array}{l}\text { Pungent pepper } \\
\text { (chillies) }\end{array}$ & Capsaicin & Skin irritation, gastric disorders \\
\hline Parsley, Celery & $\begin{array}{l}\text { Psoralens, Terpenoids, Alkaloids, } \\
\text { Choline-esterase inhibitor }\end{array}$ & Dermatitis \\
\hline
\end{tabular}

Biochemical effects of the anti-nutritional factors

The biochemical and toxicological/adverse effects of plant's secondary metabolites i.e., anti-nutritional factors have been briefly summed up as follows: Soybeans contain several anti-nutritional factors (ANFs).
Some ANFs of nutritional significance can be destroyed or inactivated by proper heat treatment (e.g. Trypsin inhibitor) and some by supplemental enzymes (NSP enzymes, phytase), while others are unaffected by the methods applied now commercially (Van Eys et al., 2004). 
Anti-nutritional factors are also known as 'secondary metabolites' in plants and they have been shown to be highly biologically active (Zank, 1991). Although most of these secondary metabolites elicit very deleterious biological responses, some of them have found a wide application in nutrition and as pharmacologically active agents (Oakenfull and Sidhu, 1989).

Conclusion of the study is as follows:

In this review paper we have discussed the basically the antinutritional factors that are normally consumed by humans animals as their diets. In diets we take cereals mostly pulses and some leafy vegetables they contains so many antinutritional factors. These antinutritional factors have so many harmful effects on humans as well as animals and also converted in their derivatives.I

In current scenario our life and body have so many complications due our diet so we should aware about cereals and pulses harmful constituents basically anitnutritional factors. These are not possible to detoxify so we can reduce a lot of quantity during processing of various stages by physical and biochemical processes.

\section{References}

Akande, K. E.; Doma, U. D.; Agu, H. O. and Adamu, H. M. (2010). Major antinutrients found in plant protein: their effect on Nutrition. Pakisthan Journal of Nutrition 9(8):827-832.

Bora, P. (2014). Anti-Nutritional factors in foods and their effects. Journal of Academia and Industrial Research 3(6): 285-290.

D'Mello, J. P. F. and Macdonald, A. M. C. (1998). Fungal toxins as disease elicitors, In J. Rose, ed. Environmental toxicology: current developments, pp-
253-289. Amsterdam, the Netherlands, Gordon and Breach Science Publishers.

Fahey, G. C. and Jung, H. J. G. (1989). Phenolic compounds in forages and fibrous feedstuffs. In: Toxicants of Plant Origin, CRC Press; Boca Raton, FL, pp. 123-190.

Felix, J. P. and Mello, D. (2000). Farm Animal metabolism and Nutrition. United Kingdom: CABI.

Fereidoon, S. (2014). Beneficial health effects and Drawbacks of Antinutrients and Phytochemicals in Food. Appl Microbial Biotechnol 97:45-55.

Fermando, R.; Pinto, M. D. P. and Pathmeswaran A. (2012). Goitrogenic Food and Prevalence of Goitre in SriLanka. J. Food Sci., 41:1076-1081.

Finotti, E.; Bertone A. and Vivanti V. (2006). Balance between nutrients and antinutrients in nine Italian potato cultivars. Food Chemistry 99:698-701.

Friedman, M.; Henika, P. R. and Mackey, B. E. (2003). Effect of feeding solanide, solasodine and tamatidine to nonpregnant and pregnant mice. Food and Chemical Toxicology 41:61-71.

Giri, A. P. and Kachole M. S. (2004). Amylase inhibitors of pigeon pea (Cajanus cajan) seeds. Phytochemistry 47:197-202.

Golden, M. (2009). Nutrient requirements of moderately malnourished populations of children. Food Nutr. Bull.

Habtamu, F. and Negussie R. (2014). Antinutritional factors in plant foods: Potential health benefits and adverse effects. International Journal of Nutrition and Food Sciences 3(4):284289.

Khokhar, S. and Apenten, R. K. O. (2014). Antinutritional factors in food legumes and effects of processing. Encyclopedia of life support system (EOLSS).

Krammer, R. P.; Hindorf, H.; Jha, H. C.; Kallage, J. and Zilliken, F. (1984). 
Antifungal activity of soyabean and cowpea isoflavones and their reduced derivatives. Phytochemistry. 23(10): 2203.

Mueller, I. (2001). Analysis of hydrolysable tannins, Anim. Feed Sci. Technol 91:320.

Nachbar, M. S.; Oppenhein, J. D. and Thomas J. O. (2000). Lectin from the tomato (Lycopersicon). J. Biol. Chem., 255:2056

Oakenfull, D. G. and Sidhu, G. S. (1989). Saponins. In: Toxicants of plant origin. 2, Glycosides, edited by P. R. Cheeke, CRC Press. Inc. Florida. 4: 97.
Shanthakumari, S.; Mohan V. and Britto J. (2008). Nutritional evaluation and elimination of toxic principles in wild yam (Dioscorea spp.). Tropical and subtropical Agroecosystems 8:319-225.

Van Eys, J. E.; Offner, A. and. Bach, A. (2004). Chemical Analysis, Manual of Quality Analysis for Soybean Products in the Feed Industry. American Soybean Association.

Zank, H. M. (1991). Chasing the enzymes of secondary metabolism: Plant Cell Cultures as a point of goal. hytochemistry 309(12): 3861- 3863.

\section{How to cite this article:}

Nitin Vikram, Sunil Kumar Katiyar, Chandra Bhushan Singh, Raja Husain and Lokesh Kumar Gangwar. 2020. A Review on Anti-Nutritional Factors. Int.J.Curr.Microbiol.App.Sci. 9(05): 1128-1137. doi: https://doi.org/10.20546/ijcmas.2020.905.123 